\title{
CONTROLE DE TIRIRICA (CYPERUS ROTUNDUS L.) COM APLICAÇÕES SUCESSIVAS DE EPTC, EM CULTURA DE FEIJÃO $\left({ }^{1,2}\right)$
}

\author{
Robert Deuber e Reinaldo Forster, Centro Experimental de Cam- \\ pinas, Instituto Agronômico
}

\section{SINOP S E}

Estudou-se o controle da tiririca (Cyperus rotundus L.) por meio de aplicaçōes sucessivas de EPTC, uma e duas vezes ao ano, por dois anos. Aliou-se a eficiência do produto contra a tiririca à sua seletividade ao feijoeiro (Phaseolus vulgaris L.), cv. carioca. As doses variaram desde 0 a $21,6 \mathrm{~kg} / \mathrm{ha}$ do ingrediente ativo, sendo que a dose máxima näo se mostrou esterilizante do solo, nem com duas aplicaçóes ao ano, o que se verificou pela população de carrapicho-de-carneiro (Acanthospermum hispidum DC) e serralha-falsa (Emilia sonchifolia L.).

Houve redução gradativa e significativa da população de tiririca, com duas aplicaçōes por ano, em todas as doses. Nas mais elevadas verificou-se redução total após dois anos. Com uma aplicação por ano, nas doses mais elevadas, houve recuperaçăo parcial, e nas mais baixas, recuperação total.

As produções e a qualidade da cultura não foram afetadas pelo herbicida. Houve aumento de produção com a elevação da dose na segunda e quarta safras, devido, aparentemente, à eliminação da competição da tiririca.

\section{1 - INTRODUÇAO}

A tiririca (Cyperus rotundus L.) tem sido um dos maiores problemas em muitas culturas, concorrendo na absorção de nutrientes e água, de modo muito intenso. Diversos herbicidas têm sido testados para o combate dessa erva, mas nas doses usuais não se conseguiu um resultado satisfatório. Waters e Burgis (16), usando terbacil, bromacil, diclobenil e $\mathrm{N}$-hidroximetil-2-6-diclorotiobenzamida, obtiveram bom controle da tiririca, mas com prejuízo para diversas culturas

(1) Trabalho apresentado na XXVIII Reuniăo Anual da Socledade Brasileira para - Progresso da Ciencia, realizada en Curitiba, Paraná, de 4 a 11 de julho de 1971. Recebldo para publicaçăo em 21 de junho de 1974.

$\left.{ }^{2}\right)$ Os autores agradecem ao Eng.o Agr.o Toshio Igue a orientaç̆o na análise 
Vol. 33, N. ${ }^{\circ} 10$

plantadas a seguir, inclusive o feijão. Com os herbicidas esterilizantes do solo é possivel erradicar a tiririca, mas na agricultura seu emprego é uma prática antieconômica, pois perde-se o solo tratado por períodos de até dois anos $(8, \mathbf{1 1})$. O EPTC (S-etil-dipropiltiocarbamato) surgiu como herbicida seletivo para o controle dessa invasora na cultura do feijoeiro, como bem o demonstram vários autores $(2,3,5,7,8,12)$. É um graminicida, e em doses de 2,7 até $10,0 \mathrm{~kg}$ de ingrediente ativo por hectare tem controlado bem a tiririca $(\mathbf{1}, \mathbf{6}, \mathbf{1 0})$. O produto, quando comparado com diversos outros, mostrou-se o mais eficiente (4), embora sua ação não persista por mais de três meses (15). Como o herbicida, mesmo em doses mais elevadas que a usual, não tem ação total sobre a tiririca, decidiu-se fazer aplicações sucessivas, como rẹalizado anteriormente por Hauser (13). Aliou-se este método à seletividade do feijoeiro, visando à erradicação da erva sem esterilizar o solo. A produção da cultura poderia contrabalançar economicamente os gastos com a aplicação do produto, mesmo em doses mais elevadas.

\section{2 - MATERIAL E MÉTODOS}

Um experimento, com duração de dois anos, foi instalado en um latossolo roxo com $48 \%$ de argila e $3,7 \%$ de matéria orgânica, que vinha sendo cultivado normalmente e que estava infestado há vários anos com tiririca (Cyperus rotundus L.), no Centro Experimental de Campinas.

Adotou-se um esquema de blocos ao acaso, com quatro repetições. Cada parcela media $3,6 \mathrm{~m}$ de largura por $4,0 \mathrm{~m}$ de comprimento. As linhas de feijão foram semeadas a $0,4 \mathrm{~m}$ com semeadeira de tração animal e na média de 10 sementes por metro linear.

Cultivou-se feijão (Phaseolus vulgaris L.) duas vezes ao ano: o cultivar chumbinho-opaco, nas duas primeiras ocasiões, e o carioca nas duas últimas. A adubação básica empregada foi de $40-80-30 \mathrm{~kg} / \mathrm{ha}$ de $\mathrm{N}, \mathrm{P}_{2} \mathrm{O}_{5}$ e $\mathrm{K}_{2} \mathrm{O}$.

Empregou-se o herbicida EPTC, que foi aplicado na forma de Eptam (formulado a $720 \mathrm{~g} / \mathrm{l}$ do produto ativo EPTC, que é S-etildipropiltiocarbamato). As doses de EPTC aplicadas foram: 0, 4,32, $8,64,12,96,17,28$ e $21,60 \mathrm{~kg} / \mathrm{ha}$. A aplicação se fez, sempre, com calda de água, por meio de um pulverizador manual Excelsior, com capacidade de 2 litros, na base de 1.000 litros de calda por hectare. A seguir, fez-se sempre a incorporação do herbicida com grade de discos dupla, a uma profundidade de $0,10 \mathrm{~m}$. 
A primeira aplicação foi feita em setembro de 1969, e a semeadura do feijão a seguir. $O$ experimento não foi capinado durante o transcorrer da cultura. Após a colheita foi feita a avaliação das ervas existentes e da área por elas coberta. Fez-se uma observação da qualidade dos grãos produzidos pela comparação dos pesos de grãos defeituosos de cada tratamento. Capinou-se a área do experimento superficialmente, e após o rebrotamento das tiriricas foi feita uma contagem delas. A seguir, o terreno foi arado e gradeado. No mês de março de 1970 fez-se a reaplicaçăo na metade de cada parcela, chamada subparcela $\mathrm{I}$, de $1,80 \mathrm{~m} \times 4,00 \mathrm{~m}$, ficando a outra metade, subparcela II, sem reaplicação. Foi feita uma avaliação de ervas e tiriricas pelo método visual, durante o ciclo desta segunda cultura. Após a colheita foi realizada a avaliação de reinfestação de ervas. Novamente se fez uma capina rasa e contagem de tiriricas após a rebrotação. A área foi então arada e gradeada para a próxima cultura de verão. Em outubro de 1970 foi feita nova aplicação, desta vez na área total. Fez-se uma contagem de tiriricas durante o ciclo da cultura.

Após a colheita, em janeiro de 1971, fez-se capina rasa e, novamente, contagem de tiririca, após o rebrotamento. O solo foi novamente preparado para outra cultura, agora de inverno, com reaplicação apenas das subparcelas I. Foi feita uma contagem de ervas e tiriricas após a colheita, no mês de junho. Aos 750 dias, a contar da primeira aplicação, fez-se nova contagem de tiriricas, sendo também coletadas duas amostras de terra de $0,20 \mathrm{~m}$ de diâmetro por $0,15 \mathrm{~m}$ de profundidade em cada subparcela, para verificar o número de tubérculos de tiririca ainda não eliminados pelo herbicida.

Para a contagem de tiriricas e de ervas foi usado um aro de $0,20 \mathrm{~m}^{2}$, na primeira contagem, e de $0,10 \mathrm{~m}^{2}$ nas demais. Foram contadas sempre três amostras em cada parcela e subparcela. Para as avaliações visuais usou-se a tabela de notas de 1 a 9 , adotada pelo European Weed Research Council.

Para avaliar a eficiência dos tratamentos compararam-se as contagens de tiriricas e as produções de feijão, por tratamento. $O$ número de tiriricas foi comparado na forma de $\log (n+2)$, sendo $n$ o número total de plantas por repetição.

Foram correlacionadas as produções de feijão e o número de tiriricas de cada tratamento. 
A produção da primeira cultura se obteve com a colheita das sete linhas centrais de cada parcela, e as das demais culturas com as colheitas das três linhas centrais de cada sub-parcela.

\section{3 - RESULTADOS E DISCUSSAO}

\section{1 - POPULAÇAO DE TIRIRICAS}

O quadro 1 mostra o número de plantas por metro quadrado, em todas as contagens, de cada tratamento.

Foram sempre consideradas as plantas nascidas, para as comparações de população de tiriricas, exceto na última contagem, quando foi considerado o número de tubérculos. Hauser (13), que realizou, também, aplicações sucessivas de EPTC em tiriricas, considerou sempre o número de tubérculos.

Os resultados das contagens de tiriricas nascidas mostram que nas subparcelas I, em que se realizaram duas aplicaçóes de EPTC por ano, houve um gradativo decréscimo da população, a partir da dose de $8,64 \mathrm{~kg}$. Esse decréscimo foi tanto maior quanto maior a dose aplicada. Com a dosagem de $4,32 \mathrm{~kg}$ năo houve decréscimo, considerando o período de 750 dias. As doses de 17,28 e 21,60 kg apresentaram controle quase total na terceira coniagem, quando já tinham sido realizadas três aplicações do herbicida.

Com uma aplicação ao ano o resultado foi negativo, pois as plantas tiveram tempo de se reconstituir, devido ao grande intervalo entre as aplicaçōes, mesmo no caso de doses elevadas. No final do periodo, nas subparcelas II, houve grande aumento da população de tiriricas, em todos os tratamentos. Verifica-se que nem mesmo uma dose de $21,60 \mathrm{~kg}$ de EPTC por hectare é suficiente para eliminar a tiririca quando se faz uma aplicação por ano em dois anos consecutivos.

A última contagem, aos 750 dias após a 1.* aplicação, foi realizada para verificar a capacidade de recuperação da tiririca. Nas duas doses mais elevadas, nas subparcelas I, verificou-se controle total da erva. A contagem de tubérculos, entretanto, mostrou que a dose de $17,28 \mathrm{~kg}$ de EPTC não eliminou a tiririca, pois foram encontrados ainda 24 deles por $\mathrm{m}^{2}$. Somente na dose máxima não se encontrou nenhum tubérculo no solo, mostrando que foram totalmente eliminados pelo herbicida. 


\begin{tabular}{|c|c|c|c|c|c|c|c|c|c|}
\hline & \multirow{2}{*}{ 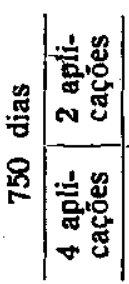 } & \multirow[t]{2}{*}{$=$} & \multicolumn{2}{|c|}{ 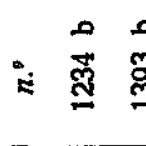 } & 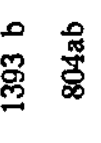 & م & 产 & \multirow{2}{*}{ 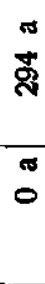 } \\
\hline & & & & : & 茼 & in & 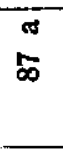 & 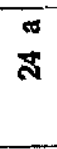 & \\
\hline 的 & : & 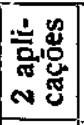 & $=$ & i. & : & 㞼 & $\begin{array}{l}\text {. } \\
\text { : } \\
8\end{array}$ & $\begin{array}{l}\text { 品 } \\
8 \\
8\end{array}$ & 蛋 \\
\hline 晜 & 8 & 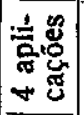 & - & $\therefore \stackrel{0}{0}$ & สิ & 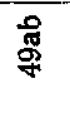 & సี & 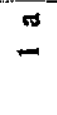 & 0 \\
\hline . & : & 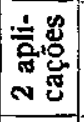 & $=$ & $\therefore 5$ & क् & 芯 & 胥 & 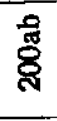 & 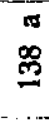 \\
\hline ข. & $:$ & 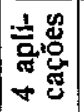 & - & ن $\stackrel{0}{*}$ & 吾 & $\stackrel{\pi}{0}$ & $\tilde{0}$ & $\ddot{0}$ & $\stackrel{0}{0}$ \\
\hline है & : & 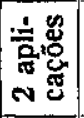 & $=$ & $\begin{array}{l}0 \\
\therefore \quad ~\end{array}$ & స్ & 苂 & 蒿 & 悉 & ̊̊ \\
\hline $\mid$ & in: & 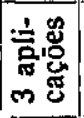 & - & ¿ & $\stackrel{\tilde{N}}{\tilde{N}}$ & $\frac{0}{\infty}$ & 号 & $\stackrel{\pi}{m}$ & " \\
\hline 量 & : & 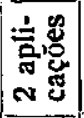 & $=$ & $\stackrel{乛}{\approx}$ & 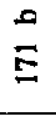 & 愚 & 怘 & $\begin{array}{l}\stackrel{0}{\pi} \\
\stackrel{7}{7}\end{array}$ & $\stackrel{\infty}{\infty}$ \\
\hline$i$ & 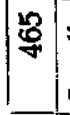 & 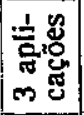 & - & ¿ 菏 & 芯 & 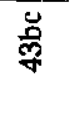 & 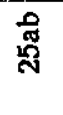 & $\pi$ & 0 \\
\hline 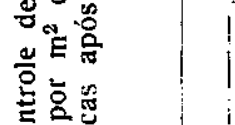 & $\mid$ & 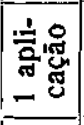 & $=$ & $\stackrel{\infty}{\infty}$ & 胥 & న్లు & $\tilde{\mathscr{E}}$ & 菏 & ह్లే \\
\hline 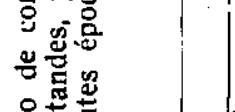 & : & 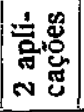 & - & $\because \overrightarrow{\mathbb{N}}$ & $\stackrel{m}{N}$ & 苞 & 胥 & 8 & q \\
\hline 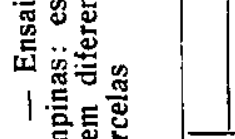 & 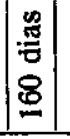 & 言。 & & $\therefore$ 兽 & $\stackrel{\pi}{\cong}$ & 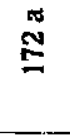 & $\frac{\pi}{5}$ & 兽 & ธ్ \\
\hline ป & 亗 & 용 & & $\stackrel{8}{8}$ & $\stackrel{N}{\sim}$ & 芯 & $\begin{array}{l}\mathscr{8} \\
\text { ऽ }\end{array}$ & 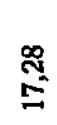 & $\frac{8}{4}$ \\
\hline
\end{tabular}


Hauser (13) aplicou a dose de $10,0 \mathrm{~kg}$ de EPTC por hectare duas vezes por ano em dois anos consecutivos e conseguiu uma redução da ordem de $90 \%$ no número de tubérculos, resultado bastante próximo ao que foi encontrado neste experimento, com a dose de $8,64 \mathrm{~kg}$.

A análise da interaçăo dose $\mathrm{x}$ número de aplicações mostrou diferenças altamente significativas tavorecendo duas aplicações por ano. O quadro das contagens evidencia claramente essas diferenças.

O tratamento sem herbicida mostrou quanto a população de tiriricas pode aumentar em área cultivada normalmente, num periodo de dois anos.

$\mathrm{Na}$ primeira contagem havia 139 plantas por $\mathrm{m}^{2}$. Esse número atingiu 740 após o período de 750 dias. $O$ número de tubérculos, entretanto, era de 1.274, o que mostra que uma grande parte estava dormente. Depois de cada cultura o solo foi arado e gradeado, eliminando totalmente as partes aéreas das plantas. Contudo os tubérculos dormentes brotavam, formando novas cadeias de tubérculos. Já foi estudada essa multiplicação por meio de tubérculos dormentes (14). Mesmo um tubérculo cortado ao meio pode brotar e iniciar uma nova cadeia (15).

Para a erradicação da tiririca, nas condições deste experimento, sāo necessárias duas aplicaçōes de $21,60 \mathrm{~kg}$ de EPTC por hectare, por ano, por dois anos sucessivos. A dose de $17,28 \mathrm{~kg}$ foi quase suficiente.

\section{2 - PRODUÇAO DE FEIJAO}

O quadro 2 mostra as produções por hectare, em cada cultura.

$\mathrm{Na}$ primeira cultura todos os tratamentos com EPTC apresentaram produçōes muito mais elevadas que no tratamento sem herbicida. A baixa produção deste tratamento foi devida à intensa competição por parte da tiririca e do capim-colonião. Deveria ter havido um tratamento mantido sempre sem ervas, mas nas condições do experimento não seria possivel eliminar a concorrência da tiririca apenas pela capina. Notou-se, pela observação visual e pelos dados de produção, que essa concorrência foi sempre muito grande. Faz-se necessário um estudo dessa competição com diversas culturas.

A escolha de grãos mal desenvolvidos e defeituosos, nas doses extremas, foi feita para verificar uma possivel ação prejudicial do her- 
QUADRO 2. - Ensaio de controle de tiririca com EPTC em cultura de feijão, em latossolo roxo do Centro Experimental de Campinas: produçóes (grãos) de feijão em cultivos "das águas" e "das secas", com reaplicaçẩo (I) e sem reaplicação (II) do herbicida nas parcelas.

\begin{tabular}{|c|c|c|c|c|c|c|c|}
\hline \multirow{4}{*}{$\begin{array}{c}\text { Dose } \\
\text { de } \\
\text { EPTC }\end{array}$} & \multicolumn{7}{|c|}{ Culturas (*) } \\
\hline & $\begin{array}{c}1 . * \\
\text { ("chuvas") }\end{array}$ & \multicolumn{2}{|c|}{ 2." ("seca") } & \multicolumn{2}{|c|}{ 3." ("chuvas") } & \multicolumn{2}{|c|}{ 4." ("seca") } \\
\hline & 1 aplicacão & $\begin{array}{l}2 \text { apli- } \\
\text { caçốes }\end{array}$ & $\begin{array}{l}1 \text { apli- } \\
\text { caçâoo }\end{array}$ & $\begin{array}{l}3 \text { apli- } \\
\text { caçōes }\end{array}$ & $\begin{array}{l}2 \text { apli- } \\
\text { caçōes }\end{array}$ & $\begin{array}{l}4 \text { apli- } \\
\text { caçōes }\end{array}$ & $\begin{array}{l}2 \text { apli- } \\
\text { caçōes }\end{array}$ \\
\hline & & I & II & I & II & 1 & II \\
\hline $\mathrm{kg} / \mathrm{ha}$ & $\mathrm{kg} / \mathrm{ha}$ & $k g / h a$ & $\mathrm{~kg} / \mathrm{ha}$ & $k g / h a$ & $\mathrm{~kg} / \mathrm{ha}$ & $\mathrm{kg} / \mathrm{ha}$ & $k g / h a$ \\
\hline $\begin{array}{r}0,00 \\
4,32 \\
8,64 \\
12,96 \\
17,28 \\
21,60\end{array}$ & $\begin{array}{r}845 \text { a } \\
1616 \text { a } \\
1960 \text { a } \\
1854 \text { a } \\
1864 \text { a } \\
1951 \text { a }\end{array}$ & $\begin{array}{l}212 \mathrm{c} \\
358 \mathrm{bc} \\
543 \mathrm{ab} \\
550 \mathrm{ab} \\
595 \mathrm{a} \\
477 \mathrm{ab}\end{array}$ & $\begin{array}{l}210 \text { a } \\
183 \text { a } \\
204 \text { a } \\
268 \text { a } \\
287 \text { a } \\
320 \text { a }\end{array}$ & $\begin{array}{r}764 \text { a } \\
948 \text { a } \\
1350 \text { a } \\
1664 \text { a } \\
1691 \text { a } \\
1629 \text { a }\end{array}$ & $\begin{array}{r}608 \mathrm{a} \\
450 \mathrm{a} \\
804 \mathrm{a} \\
971 \mathrm{a} \\
843 \mathrm{a} \\
1273 \mathrm{a}\end{array}$ & $\begin{array}{l}231 \text { c } \\
554 b c \\
750 a b \\
914 \text { a } \\
912 a \\
610 a b\end{array}$ & $\begin{array}{r}142 \mathrm{c} \\
89 \mathrm{c} \\
168 \mathrm{c} \\
227 \mathrm{bc} \\
312 \mathrm{ab} \\
425 \mathrm{a}\end{array}$ \\
\hline
\end{tabular}

(*) Valores nas colunas, seguldos de letras tguais, năo diferem entre si ao nivel de $5 \%$ (teste de Tukey)

bicida sobre a qualidade da produçăo. Não se verificou nenhuma diferença.

A segunda cultura foi conduzida no tempo da seca, tendo, por isso, apresentado produções baixas. Nas subparcelas I houve diferenças entre tratamentos, tendo o de $17,28 \mathrm{~kg} / \mathrm{ha}$ produzido mais. Nas subparcelas II não se verificaram diferenças, mostrando que o efeito herbicida sobre as tiriricas já tinha praticamente desaparecido.

Foi feita a escolha de grãos com defeito em todos os tratamentos, não se verificando diferenças entre nenhum deles.

$\mathrm{Na}$ terceira cultura, agora do tempo das chuvas, não houve nenhuma diferença entre tratamentos.

$\mathrm{Na}$ última cultura verificaram-se diferenças significativas, tendo os tratamentos com doses de 12,96 e $17,28 \mathrm{~kg}$ de EPTC produzido mais nas subparcelas I, e os com doses de 17,28 e 21,60 produzido mais nas subparcelas II.

Verificou-se em todos os anos, fitotoxicidade leve nas doses mais elevadas, que se caracterizou por uma coloraçăo verde intensa das folhas e um ligeito retardamento inicial de crescimento. $\mathrm{Na}$ última cultura houve fitotoxicidade de grau severo no início do ciclo, causando 
reduçāo de número de plantas e de produção na dose máxima, na subparcela I. Nas duas doses mais elevadas verificou-se, também, um atraso de sete dias no fim do ciclo da cultura. A redução de produção causada pelo herbicida foi, entretanto, menor que a causada pela competição da tiririca.

As produções nas subparcelas 1 foram sempre maiores que nas subparcelas II, tendo sido maiores as diferenças nas doses mais baixas, o que se explica pelo efeito residual favorável mais longo nas doses elevadas. Assim, mesmo com uma aplicaçāo por ano, nas doses mais elevadas reduziu-se bastante a competição da tiririca.

Pelos dados obtidos observa-se que, à medida que aumentou a dose do herbicida, aumentou também a produção de feijão. Isso foi devido à eliminação gradativa da tiririca, que teve, assim, a sua competição diminuída. Não parece que o aumento da dose do herbicida tenha favorecido diretamente o feijociro.

\section{3 - CORRELAÇAO ENTRE A PRODUÇAO E O NÚMERO DE PLANTAS DE TIRIRICA}

A observação dos quadros de produção de feijão e de nủmero de plantas de tiririca sugeria uma correlaçāo negativa entre esses valores. Foi feita, por esse motivo, a análise da correlação, obtendo-se valores significativos, a partir da segunda cultura. Os coeficientes de determinação $\left(\mathrm{r}^{2}\right)$ năo foram, entretanto, elevados. As porcentagens da soma dos quadrados totais atribuíveis à regressão produção $\mathrm{x}$ número de plantas de tiririca foram as seguintes:

$\begin{array}{cccc}\text { CUL.tURA } & N .^{\circ} \text { de aplicaçöes } & \text { \% e significância } \\ 1 . * & 1 & 2 & \text { n.s. } \\ 2 . * & 2 & 23 & * \\ & 1 & 28 & * \\ 3 . * & 3 & 48 & * * \\ & 2 & 35 & * * \\ 4 . * & 4 & 18 & * \\ & 2 & 18 & *\end{array}$

Na primeira cultura não se obteve resultado mais elevado porque a contagem de plantas de tiririca se fez depois da colheita, já com tempo para recuperação sensivel delas. 


\section{4 - POPULAÇAO DE OUTRAS ERVAS}

A observação da população de outras ervas invasoras foi realizada para verificar até que ponto o solo poderia ser esterilizado. 0 quadro 3 mostra a área coberta por essas ervas.

QUADRo 3. - Ensaio de controle de tiririca com EPTC em cultura de feijāo, em latossolo roxo do Centro Experimental de Campinas: áreas (\%) cobertas por outras ervas, em quatro avaliaçóes visuais segundo EWRC, feitas em diferentes épocas após o tratamento do solo em pté-plantio, com (I) e sem (II) reaplicação do herbicida nas parcelas

\begin{tabular}{|c|c|c|c|c|c|c|c|}
\hline \multirow{4}{*}{$\begin{array}{l}\text { Dose } \\
\text { de } \\
\text { EPTC }\end{array}$} & \multicolumn{7}{|c|}{ Protocolos } \\
\hline & \multirow{3}{*}{$\begin{array}{l}140 \text { dias } \\
1 \text { aplicaçāo }\end{array}$} & \multicolumn{2}{|c|}{220 dias } & \multicolumn{2}{|c|}{370 dias } & \multicolumn{2}{|c|}{680 dias } \\
\hline & & $\begin{array}{l}2 \text { apli- } \\
\text { caçoes }\end{array}$ & $\begin{array}{l}1 \text { apli- } \\
\text { caçáo }\end{array}$ & $\begin{array}{l}2 \text { apli- } \\
\text { caçōes }\end{array}$ & $\begin{array}{l}1 \text { apli- } \\
\text { cação }\end{array}$ & $\begin{array}{l}4 \text { apli- } \\
\text { caçốes }\end{array}$ & $\begin{array}{l}2 \text { apli- } \\
\text { caçōes }\end{array}$ \\
\hline & & 1 & II & I & 11 & I & II \\
\hline$k g / h a$ & $\%$ & $\%$ & $\%$ & $\%$ & $\%$ & $\%$ & $\%$ \\
\hline $\begin{array}{r}0,00 \\
4,32 \\
8,64 \\
12,96 \\
17,28 \\
21,60\end{array}$ & $\begin{array}{r}100 \\
70 \\
40 \\
25 \\
25 \\
15\end{array}$ & $\begin{array}{l}5 \\
4 \\
1 \\
1 \\
0 \\
0\end{array}$ & $\begin{array}{r}10 \\
5 \\
6 \\
5 \\
35 \\
20\end{array}$ & $\begin{array}{r}100 \\
75 \\
40 \\
15 \\
5 \\
5\end{array}$ & $\begin{array}{r}100 \\
90 \\
100 \\
100 \\
100 \\
90\end{array}$ & $\begin{array}{r}100 \\
25 \\
10 \\
5 \\
5 \\
1\end{array}$ & $\begin{array}{r}100 \\
100 \\
95 \\
100 \\
75 \\
75\end{array}$ \\
\hline
\end{tabular}

A primeira observação se fez 140 dias após a primeira aplicação, quando se avaliou a área coberta e as ervas predominantes. O tratamento sem herbicida apresentava principalmente capim-colonião (Panicum maximum Jacq.), Gramineae, e tiririca (Cyperus rotundus L.), Cyperaceae. Além dessas, ororreram o carrapicho-de-carneiro (Acanthospermum hyspidum DC), Compositae, vassourinha (Lepidium virginicum L.), Cruciferae, quenopódio (Chenopodium album L.), Chenopodiaceae, caruru-comum (Amaranthus virides L.), Amaranthaceae, beldroega (Portulaca oleracea L.), Portulacaceae, e serralha-falsa (Emilia sonchifolia L.) Compositae. Todos os tratamentos com herbicidas apresentavam essas ervas.

A segunda avaliação da área coberta foi feita a apenas 30 dias após a segunda aplicação, apresentando, por isso, tão pouca área coberta, em todos os tratamentos.

$\mathrm{Na} 3 .^{*}$ e 4.* avaliações observou-se um decréscimo sensível de área coberta à medida que aumentavam as doses, sendo menor a área coberta nas subparcelas 1 . Esses dados atestam que houve também 
um controle geral de ervas de folhas largas. Nas subparcelas I, os tratamentos com 0 e $4,32 \mathrm{~kg}$ apresentavam principalmente tiririca, ao passo que os tratamentos com doses acima de $8,64 \mathrm{~kg}$ mostravam as ervas de folhas largas já mencionadas. As subparcelas II sempre apresentavam tiririca e maior proporção de ervas de folhas largas, em todos os tratamentos. Observa-se que houve controle quase total nos tratamentos com doses mais elevadas, mas a serralha-falsa e o carrapicho-de-carneiro mostraram-se resistentes.

\section{4 - CONCLUSOES}

Para o solo descrito o experimento permitiu concluir:

a) Foram suficientes duas aplicaçōes de $21,60 \mathrm{~kg} / \mathrm{ha}$ de EPTC por ano, durante dois anos, para eliminar totalmente a tiririca, ao passo que uma aplicação dessa dose por ano não foi suficiente nem mesmo para reduzir a população.

b) O feijoeiro (Phaseolus vulgaris L.) tolera satisfatoriamente as aplicaçōes sucessivas de EPTC, mesmo em doses elevadas. Houve aumento de produçāo de feijāo com o aumento da dose de EPTC, o que foi devido à eliminação da competição da tiririca.

c) A serralha-falsa (Emilia sonchifolia L.) e o carrapicho-decarneiro (Acanthospermum hyspidum DC) são ervas resistentes ao herbicida EPTC até em doses de $21,60 \mathrm{~kg} / \mathrm{ha}$, aplicado duas vezes ao ano, por dois anos.

\section{CONTROL OF NUTSEDGE (CYPERUS ROTUNDUS L.) WITH SUCESSIVE APPLICATIONS OF EPTC ON BEANS}

\section{SUM M A R Y}

The control of nutsedge (Cypertus rotundus L.) with sucessive applications of EPTC was studied, during two years, combining the selectivity of the herbicide to beans (Phaseolus vulgaris L.) and its efficiency against the weed, even with two applications per year. The rates ranged from 4.32 to $21.60 \mathrm{~kg} / \mathrm{ha}$ of EPTC. The highest rate did not sterilize the soil, even with two applications per year. 
There was a gradual and significant reduction of the nutsedge population at all rates with two applications per year. The weed had time to recover with only one application per year even with the highest rate, but was totally killed by it with two applications after two years.

The bean quality and yields were not affected by the herbicide. There was an increase of yields with the increasing of the EPTC rates, due, apparently, to the elimination of the nutsedge competition.

\section{LITERATURA CITADA}

1. ALMEIDA, F. S. \& FONSECA, A. M. Contribuição ao estudo da eficiência do EPTC em Cypertus rotundus L. Agronomia Moçambicana 1(4): 215-221, 1967.

2. ALVES, A. \& BERNARDI, J. B. Controle de ervas em feijão com herbicidas. In: SEMINARIO BRASILEIRO DE HERBICIDAS E ERVAS DANINHAS, 6., Sete Lagoas, 1966 . Anais. p.257-262.

3. BARNES, W. C. \& SITTERLY, W. R. Control of nutsedge and other weeds in vegetable crops. Proc. Am. Soc. hort. Sci. 83:728-733, 1963.

4. CHURCH, J. M. F. \& HENSON, H. M. G. Chemical control of Cyperus rotundus L. and Oxalis latifolia in Uganda. PANS 15(4):578-583, 1969.

5. COELHO, J. P. \& VAL, W. M. C. Uso de herbicidas em feijão das águas. In: SEMINARIO BRASILEIRO DE HERBICIDAS E ERVAS DANINHAS, 6., Sete Lagoas, 1966. Anais. p. 129-132.

6. CRUZ, R.; ROMERO, C. \& CARDENAS, J. Control de Cyperus rotundus en el Vale de Sinu. In: SEMINARIO DE LA SOCIEDAD COLOMBIANA DE CONTROL DE MALEZAS Y FISIOLOGIA VEGETAL, 1 , Bogotá, 1969. Resumenes. p.60-61.

7. DEUBER, R. \& FORSTER, R. Ensaios de herbicidas em culturas de feijão (Phaseolus vulgaris L.). Campinas, Instituto Agronômico, 1974. 28p. (Bol. técnico, 13)

8. ELAL, G.; ALON, Y. \& LUZ, E. Selective herbicides for pre-emergence weed control in beans. In: ISRAEL WEED CONFERENCE, 2., 1965. Proceedings. p.21.

9. FORSTER, R. $\mathrm{O}$ uso do CMU como herbicida total. Bragantia 16: XXVII-XXI, 1957. (Nota 6)

10. ㄴ... Observações preliminares da aplicação de Eptam em préemergência. In: SEMINARIO BRASILEIRO DE HERBICIDAS E ERVAS DANINHAS, 3., Campinas, 1960 . Anais. p.109-116. 
11. FORSTER, R. Hyvar - Avaliação de um herbicida para ação total em três ervas problemas: tiririca, sapé e samambaia. In: SEMINARIO BRASILEIRO DE HERBICIDAS E ERVAS DANINHAS, 5, Cruz das Almas, 1964 . p.37-45.

12. \& ALVES, A. Observaçōes do uso de Eptam para controle de ervas más na cultura do feijăo. In: SEMINARIO BRASILEIRO DE HERBICIDAS E ERVAS DANINHAS, 3., Campinas, 1960. p. 267-282.

13. HAUSER, E. W. Response of purple nutsedge to amitrole, 2,4-D and EPTC. Weeds 11(4):251-252, 1963.

14. RAO, I. S. Studies on the development of tubers in nutgrass and their starch content at different depths of soil. Madras agric. J. 55(1): 19-23, 1968.

15. SALAZAR, E.; NAVIA, D. \& CARDENAS, J. Resultados de la investigacion sobre el Cyperus rotundus $L$. en el Ecuador. IN REUNION LATINOAMERICANA DE FITOTECNIA, 8., Colombia, 1970. Resumenes. p.155.

16. WATERS, W. E. BURGIS, D. S. Herbicidal persistence in soil and its effect on purple nutsedge. Weed Science 16(2):149-151, 1968. 